\title{
On the Theory and Practice of CYL's Innovative Construction
}

\author{
Mingxiao Sui \\ Department of Electrical Engineering, Harbin University of Science and Technology Rongcheng \\ Campus, Rongcheng 264300, China \\ bkidult@gmail.com
}

Keywords: Colleges and universities, student association, CYL construction, innovation.

\begin{abstract}
The thesis, by taking Communist Youth League (referred in the text as CYL) construction in university student associations as research object, analyses its main problems and then proposes targeted solutions in term of theory, organizing and innovative administrations accordingly so as to further promote the general innovation in CYL construction.
\end{abstract}

\section{Introduction}

CYL's innovative construction refers to the active adaption, spontaneous improvement and consciously improvement of CYL organization despite changing evolving environments. The fundamental purpose is to enhance the inherent vitality of the organization, thereby a solid foundation can be consolidated and weak links be strengthened. CYL's innovative construction is a new development points for CYL organizations in colleges \& universities and also one of the supporting measures of higher education reform [1].

\section{Importance of CYL's Innovative Construction}

Innovative construction is the demand of CYL organization to take its responsibilities. Both Communist Party and CYL have defined in their constitutions that CYL is the communist party's assistant and reserve force and its role is to assist the communist party to gather support from majority of the youth [2]. Innovative construction in CYL organization could effectively organize and mobilize its members in their practice of its role and promote the development of advanced productive forces \& culture. It also helps to promote individuals' talent and their service in social practice and to further consolidate as well as expand the party's youth mass base.

Innovative construction is required by CYL's self-development. CYL's history is a process of constant self-deepening, improvement, correction and development. Currently the overall CYL construction in colleges and universities has developed to higher and more mature level but also into a "hovering" period, continuous innovative thinking are urgently needed to strengthen and improve CYL's construction.

Innovative construction of CYL assists to maintain its advancement. CYL is a youth mass organization of advancement, and its advancement is based on a broad mass base. The advanced beliefs \& goals of CYL serve in full accordance with its character of wide mass; the same is applied to the advancement of CYL organization and the advancement of its members. To maintain its 
advancement, it is required to execute constant advancement construction and innovative construction in CYL organization.

CYL's innovative construction is needed to serve majority of the youth. With the deepening of reform \& development, youth groups are undergoing tremendous changes like value diversification, lack of faith and extending individuality. These new changes may reduce CYL's sense of the sacred among its members. Besides, the phenomenon of "everybody is a CYL member" in colleges and universities also lessens the appeal and cohesion in CYL. There must be actions to meet to "consider the characteristics of the youth and "actively explore new ways to strengthen CYL construction under the new circumstance, only then CYL can continuously consolidate its cohesion while providing majority of youth better service [3].

\section{Existing problems in CYL branch construction in university student associations.}

Rationality of the league branch in student associations and the multiplicity in members' identities. CYL's branch construction in student associations, as a new thing, has neither available theory nor experience for its practical reference. Practice usually is only carried out with experience from brother colleges or just one's own exploration. Theory comes from practice and should guide the practice. Without the guidance by theory, CYL construction in student associations and relevant exploration cannot go further in depth.

Members of student association are of multi sources and highly mobility. In most cases, association members may belong to several college departments or CYL organizations. Multiplicity in their members' identities and organization structure will definitely occur if to set up CYL branches in associations built on students' interests, hobbies, profession and other core cohesions. Therefore, to set up CYL branches in student associations and achieve the organization's goal of "covering all youth and affecting all youth,", it is necessary to further enrich CYL's organization theory, to address the new situation as well as new problems emerging in practice. Achievements of student association construction will be affected if these problems remain unsolved [4].

The existing organization structure of CYL in universities is relatively simple. With new developments such as complex student sources, diversification of target groups' requirements, implementation of campus logistics service's socialization and the new credit system \& education reform, the attraction \& cohesion of the existing student administration mode based on class unit have gradually weakened, meanwhile student associations oriented by students' interests, hobbies etc are rising rapidly and becoming an important form of student organization. The evolvement has impacted more and more on students' behavior and ways of thinking.

The existing student administration mode focuses more on forms such as grand opening ceremony, closing ceremony and bustling commendation conference etc., rare attention is paid to the physical process. Insufficient understanding of the effectiveness of CYL member's participation to innovative CYL construction has resulted in too much overlook of valuable experience. Therefore, it is necessary for CYL organization at all levels in the university to work out solutions to improving CYL organization structure in universities in order to meet needs of evolving practice 
The administration system in university student association is incomplete. Currently, most university student associations are still adopting an administrative mode of "policy guidance as primary, indirect administration as complementary". In most cases, the innovation in league construction is merely referred equally as innovation in of league organizations. The administration is neither of system nor of any depth or accuracy, which has limited the innovative thinking and the effectiveness of it. In my opinion, student association is greatly different from mass organization like student union or CYL branch in composition and missions. Association members are not only of mass character but also of strong autonomy, which adds difficulty in CYL administration. There are also researches indicating that the absence of systemic administration such as the instructor's guidance and the unevenness in the personal quality of association's principal has also caused the bottleneck problem.

\section{Solutions to improve CYL construction in university student associations}

Refine CYL construction theory to rationalize CYL branches in student associations. CYL's innovative construction requires the innovation in theory as guidance. As mentioned above, there are two key problems: Rationality of CYL branches in student associations and the multiplicity in its members' identities. CYL's organization structure must adapt to new changes in youth's study, life and work under the new circumstance. Coexistence of multiple forms could be admitted to break limits in administrations and organizations. Furthermore, to acknowledge the CYL branch in the student associations would also rationalize multiple identities of association members and therefore grant obligations and responsibilities to the CYL organizations where they belong.

Establish CYL branches in student associations to refine the simple structure of CYL organization. Exploration of CYL organization's new form and CYL's expansion into student associations both could facilitate CYL's effective coverage over the youth and also create a platform of education \& communication for the members. In addition, advocating of organizing CYL branches on blog, QQ, Fetion, Weibo etc., also helps to improve and refine the construction in practice. These new forms of CYL organizations in virtual space could function in five ways: First, it helps to enrich and refine the CYL organization form; Second, it could strengthen the "autognosis" among association members and then enhance their sense of belongings. Third, it resolves CYL's structural slackness by difference in members' complex backgrounds. Fourth, CYL activities carried out on the internet could flexibly "attract and educate" those young student online; last but most importantly, the freedom and novelty on the internet would surely attract more attention \& participation into the innovative construction of CYL, which is not only beneficial for the informatization of CYL's network but also enhance the impact and transparency of CYL's activities.

Renew the administration system of CYL construction in student associations to improve CYL's administration. The administration of CYL construction should highlight its emphasis and more importantly untie its members for more options of innovative solutions. Associations oriented by theory study, science \& technology and social service should be encouraged so as to provide targeted guidance for associations of different categories. Competition mechanism, responsibility system need to be introduced for student cadre selection. Besides, there must be examination measures as well as rewards\& punishment system to standardize student cadres' activities. There should be regular inspections and examinations to improve the general quality of student 
associations and their cadres, also to ensure that all faults are rectified timely for the healthy development of student associations.

Under the development pattern of "one body two wings" proposed by central department of CYL, the CYL construction should combine with the ongoing education reform and CYL construction situation. It is of extraordinary significance to strengthen the league construction in student association in innovative ways. On one hand to establish league branches in university student associations could expand CYL's influence and coverage over the youth, on the other hand it would effectively integrate more cohesion inside the association as to benefit the development of university student associations

\section{Reference}

[1]Jinhua Zhao, Promote the innovation in league building and explore the new development in university CYL work [J], Journal of Hefei University of Technology (Social Science Edition), 2006, 20(2):32-35.

[2] Sheng Chen, A Brand-new View on the CYL work [M], Beijing: China Youth Press, 1999:9.

[3]Kan Xia, Thoughts on innovative construction of CYL in universities [J], Journal of Nanjing University of Technology (Social Science Edition), 2006, 9.

[4]Ping Chen and Yuehan Wang, Brief discussions on innovative CYL building in universities [J], China Forestry Education,2011, 1. 